\title{
Inhibitive Effect of L-Lysine on the Corrosion of Mild Steel in Acidic Solutions
}

\author{
Xingwen Zheng ${ }^{1,2, *}$, Min Gong ${ }^{2}$, Chuan Liu ${ }^{2}$ \\ ${ }^{1}$ School of Chemical and Environmental Engineering, Sichuan University of Science \& Engineering, \\ Zigong 643000, China \\ ${ }^{2}$ Key Laboratory of Material Corrosion and Protection of Sichuan Province, Zigong 643000, China \\ "E-mail: zxwasd@126.com
}

doi: $10.20964 / 2017.06 .33$

Received: 5 February 2017 / Accepted: 11 April 2017 / Published: 12 May 2017

\begin{abstract}
The inhibition performance and mechanism of L-lysine for the corrosion of mild steel in acidic solutions were investigated using electrochemical measurements and Quantum chemical calculation. The results revealed that L-lysine acted as a mixed-type inhibitor with a predominantly cathodic action for mild steel in $1 \mathrm{M} \mathrm{HCl}$ solution, but as a modest cathodic inhibitor for mild steel in $0.5 \mathrm{M} \mathrm{H}_{2} \mathrm{SO}_{4}$ solution. The adsorption of L-lysine on steel surface obeyed Langmuir adsorption isotherm, and the thermodynamic parameters were further determined based on the model. Moreover, quantum chemical calculation gave further insight into the mechanism of inhibition of L-lysine. Besides, the synergistic inhibition effect of L-lysine and chloride ion was also observed for the corrosion of mild steel.
\end{abstract}

Keywords: Mild steel; L-lysine; Acidic solutions; Adsorption isotherm; Quantum chemical calculation.

\section{FULL TEXT}

(C) 2017 The Authors. Published by ESG (www.electrochemsci.org). This article is an open access article distributed under the terms and conditions of the Creative Commons Attribution license (http://creativecommons.org/licenses/by/4.0/). 